\title{
Biology of Rhembobius quadrispinus (Hymenoptera: Ichneumonidae): Pupal parasitoid of saprophagous species of syrphids (Diptera: Syrphidae)
}

\author{
Pilar HuRTado, Celeste PÉREZ-BAÑón and Santos ROJO \\ CIBIO (Centro Iberoamericano de la Biodiversidad), Universidad de Alicante, Alicante E-03080, Spain; \\ e-mails: pilar.hurtado@ua.es; celeste.perez@ua.es; santos.rojo@ua.es
}

Key words. Hymenoptera, Ichneumonidae, Rhembobius quadrispinus, host preference, biological control, parasitoid age, Diptera, Syrphidae, Eristalis tenax, Eristalinus aeneus, Diapria conica, synanthropy, pig farms

\begin{abstract}
Little is known about the life cycle of Rhembobius parasitoids (Hymenoptera: Ichneumonidae). Known host records are mainly from saprophagous species of hoverflies of the tribe Eristalini (Diptera: Syrphidae), whose larvae develop in a wide range of aquatic and semi-aquatic breeding sites that are rich in microbial decay. We present an account of the biology and important details of the life cycle of the pupal parasitoid R. quadrispinus in both natural and controlled conditions. Host suitability, the influence of host pupal age and age of the female parasitoid on her production of progeny was evaluated in laboratory tests. Our results showed that the percentage of pupae of E. tenax that were parasitized by R. quadrispinus decreased as pupae matured, and the optimal age for successful parasitism ranged from 1 to 3 days. This biological information could be useful in the biological control of anthropophilic saprophagous eristalines that can act as potential mechanical vectors of pathogens on farms.
\end{abstract}

\section{INTRODUCTION}

The relationship between host type and suitability is an essential approach in the study of biological control with parasitoids (Vinson \& Iwantsch, 1980; Ueno, 2004). The host provides all the nutritional and physiological requirements for the immature development of insect parasitoids. Consequently, the offspring fitness of parasitoid wasps is dependent on the quality of the host, which may depend on the species, its size or stage of development, as well as the age of the stage parasitized (Charnov \& Skinner, 1984; King, 1987; Godfray, 1994).

Host size is one of the most important factors determining host suitability for many parasitoid species (King, 1987; Godfray, 1994). Host size at oviposition closely reflects the amount of food available to the offspring of idiobiont parasitoids that attack non-feeding host stages (eggs or pupae) (Arthur \& Wylie, 1959; Corrigan \& Lashomb, 1990; Otto \& Mackauer, 1998).

Pupal age is another of the main factors determining whether a pupa is accepted as a suitable host by pupal parasitoids (Ueno, 1997, 2004; Husni et al., 2001). Many physiological changes occur during the pupal stage: as a pupa ages the larva is dramatically converted into an adult. The quality and amount of food available to parasitoid offspring may be affected by this process. Old pupae may provide less food for the development of parasitoid offspring.

The genus Rhembobius Föster, 1869 belongs to the tribe Phygadeuontini, of the subfamily Cryptinae (Hymenoptera, Ichneumonidae). This tribe comprises 123 genera, which mainly parasitize species of those families of insects that produce pupae (cocoons), or cocoon-like structures, or groups that produce egg-cases, such as spiders (Yu et al., 2005). The genus Rhembobius Föster, 1869, is a small group of 9 species whose life cycles are poorly known.
Their geographical distribution is limited to the Holarctic and Oriental Regions, with 4 species in the Western Palearctic (Yu et al., 2005).

There are only host records for 4 species of the genus Rhembobius, which are mainly pupal parasitoids of several species of hoverflies (Syrphidae), which have a wide range of different larval feeding habits (phytophagous, predaceous and saprophagous) (Pisica, 1983; Sedivy, 1986; Fabritius, 1990; Horstmann, 2000; Rotheray \& Macgowan, 2000; Birtele, 2004; Schwarz \& Shaw, 2010).

Rhembobius quadrispinus (Gravenhörst, 1829) is a large solitary pupal parasitoid, producing one offspring per host. Two species of Microlepidoptera: Agonopterix nervosa (Haworth, 1811) and Loxostege sticticalis (Linneus, 1761) are cited as hosts (Constantineanu \& Mustata, 1973; Pisica $\&$ Fabritius, 1979). However, this species is frequently recorded parasitizing anthropophilic saprophagous species of syrphids of the tribe Eristalini. The species Eristalis tenax and Eristalinus aeneus are the most common hosts of $R$. quadrispinus (Pisica \& Fabritius, 1979; Horstmann, 2000), but it is also recorded parasitizing pupae of E. arbustorum and E. sepulchralis (Sedivy, 1986; Fabritius, 1990). These species of syrphids frequently occur in environments where there is a high level of organic and microbial contamination from manure on cow and pig farms, where they are potential mechanical vectors of pathogens or cause of myiasis (Catts \& Mullen, 2002; Fisher et al., 2006).

The aim of this study is to increase our knowledge about the life cycle of $R$. quadrispinus and its interaction with its hosts. The following aspects were studied: annual activity under natural conditions, developmental period, adult longevity, mating and oviposition behaviour, host suitability, the effects of host pupal age and parasitoid age at oviposition on their offspring under laboratory conditions. Finally, 
an analysis of the changes in host pupal weight during parasitoid development is also presented.

\section{MATERIAL AND METHODS}

The insects used in this study were collected from three pig farms located in Los Serranos region, Valencia Province (SE Spain) and forms part of the Life-Ecodiptera project (www. ecodiptera.info). Farms were sampled twice monthly, from May 2006 to September 2007. Adult parasitoids flying or wandering among the syrphid pupae on the ground close to the manure pools were caught with the aid of a net. They were also obtained from the approximately 50 hoverfly pupae randomly collected from the soil surface, or above the crust of the slurry at the farms at each visit. Newly emerged parasitoids were kept individually in plastic containers $(10.5 \times 10.5 \times 5 \mathrm{~cm})$ that contained a solution of dilute honey and water in cotton wool balls, until their sex and identification was confirmed. The honey solution was replaced every two days to avoid contamination by fungi.

The host pupae were obtained from mature hoverfly larvae (L3) collected at the pig farms, which were reared in the laboratory in plastic trays $(31.5 \times 20 \times 6.5 \mathrm{~cm})$, using pig manure or an oat-based medium and following the rearing protocols proposed by Gladis (1994). The host species we used were Eristalis tenax and Eristalinus aeneus. Both parasitoid and syrphid cultures were kept in a growth chamber at $20 \pm 4^{\circ} \mathrm{C}, 65 \pm 5 \% \mathrm{r}$. h. and a constant photoperiod of 10L : 14D. Under these conditions, the pupal developmental time of both hosts was $8-9$ days. When required, new syrphid pupae were collected daily and kept separately based on their age: $1,2,3,4,5,6$ or 7 days old.

\section{Biology and behaviour}

The life cycle of the parasitoids and their interaction with hosts were studied under both artificial and natural conditions. Samples collected at the farms were used to study their annual activity and host selection. Mating and oviposition behaviour of $R$. quadrispinus were studied under laboratory conditions.

\section{Host suitability}

The suitability of the pupae of E. tenax and E. aeneus as hosts for Rhembobius was studied. This was done in the laboratory using a no-choice experiment. Four pupae (1-4 days old) were placed in a Petri dish $(3.5 \mathrm{~cm}$ diameter $)$ along with a mated female (1-15 days old) for $24 \mathrm{~h}$. A total of 100 pupae of $E$. tenax and 64 pupae of $E$. aeneus were exposed to female parasitoids. The percentage of the pupae of each species that gave rise to parasitoids was used as a measure of host suitability.

\section{Effect of host pupal and parasitoid age}

Newly emerged Rhembobius wasps were paired and placed in the plastic containers. After mating, males were removed from the containers. In order to determine the preference of female wasps for host pupae of different ages, pupae were divided into seven age classes: 1, 2, 3, 4, 5, 6 or 7 days old. Four pupae, from each age group, were placed in a Petri dish $(3.5 \mathrm{~cm}$ diameter $)$ with a single female for $24 \mathrm{~h}$. Pupae of these age groups were offered randomly to single female parasitoids that were from 1 to 15 days old. A total of 216 E. tenax pupae were used (32, 44, 40, 36, 24, 20 and 20 from each age group respectively). Afterwards, all host pupae were placed and kept individually in Petri dishes and checked daily until a wasp or syrphid emerged.

To determine the effect of female parasitoid age, 4 pupae (1-3 days old) of $E$. tenax, were offered every three days to single mated females from the day on which they emerged until their death. Twelve newly emerged females were used in this experiment.
Change in the pupal weight of the host during parasitoid development

To determine the development of the parasitoid the weights of 96 pupae of E. tenax parasitized at different ages (1, 2, 3, 4, 5 or 6 days old) were weighed daily using a precision balance (Acculab, ALC-110.4). Weight of parasitized pupae was compared with that of non-parasitized pupae $(\mathrm{n}=83)$. Five pupae of $E$. tenax of each age group (1, 2, 3, 4, 5, 6 and 7 days) were dissected to determine the morphological changes occurring during the metamorphosis of non-parasitized pupae. Parasitized pupae $(n=50)$ were dissected every 3 days in order to determine the stage of development of the immature stages of $R$. quadrispinus. We used a camera (Canon Power Shot S40) connected to a LEICA MZ95 stereoscopic microscope connected to a laptop (Apple MacBook Pro).

\section{Statistical analysis}

Data were analyzed using statistical software SPSS Statistics 17.0. The arithmetic mean and standard errors (SE) are indicated. Parametric (ANOVA) and non-parametric (Kruskal-Wallis ANOVA followed by Mann-Whitney U-Test after application of Bonferroni correction) tests were used depending on the nature of the data.

\section{RESULTS}

\section{Parasitoid biology and behaviour}

We collected 1,420 syrphid pupae during the course of this study, $90 \%$ of which were E. tenax and the rest Eristalinus aeneus. Of these pupae $21.5 \%$ were parasitized and syrphids emerged from $22.3 \%$. Only $1 \%$ of the pupae of $E$. tenax were parasitized by $R$. quadrispinus and most of the rest by gregarious wasps of the family Diapriidae (20.9\%), which were identified as Diapria conica (Fabricius, 1775). The percentage parasitism of Eristalinus aeneus pupae was $2.11 \%$ and they were only parasitized by Diapria conica.

Eristalis tenax pupae were available almost all the year round on the pig farms studied (Fig. 1), with peaks in the activity of the adults recorded in early summer and autumn. There were fewer larvae of Eristalinus aeneus than E. tenax and they were present only from April to November and adults showed the same activity pattern as E. tenax. Parasitized hoverfly pupae were mainly found during the peaks in syrphid activity.

Rhembobius quadrispinus is conspicuously sexually dimorphic (white spot on female antennae). The average life span of females $(19.85 \pm 3.70$ days; $n=13$ females $)$ was longer than that of males $(7.29 \pm 0.70$ days; $n=42 ; M-W$ test $=90.50, \mathrm{p}<0.05)$. However, at least one female lived for 46 days. Both males and females mated successfully within $24 \mathrm{~h}$ of emergence, but apparently only males ac-

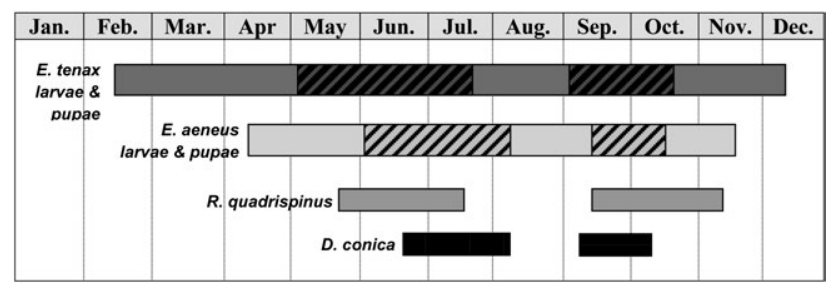

Fig. 1. Annual activity of hoverflies and parasitoids recorded in the study area. The stripes indicate the periods when adults were active. 

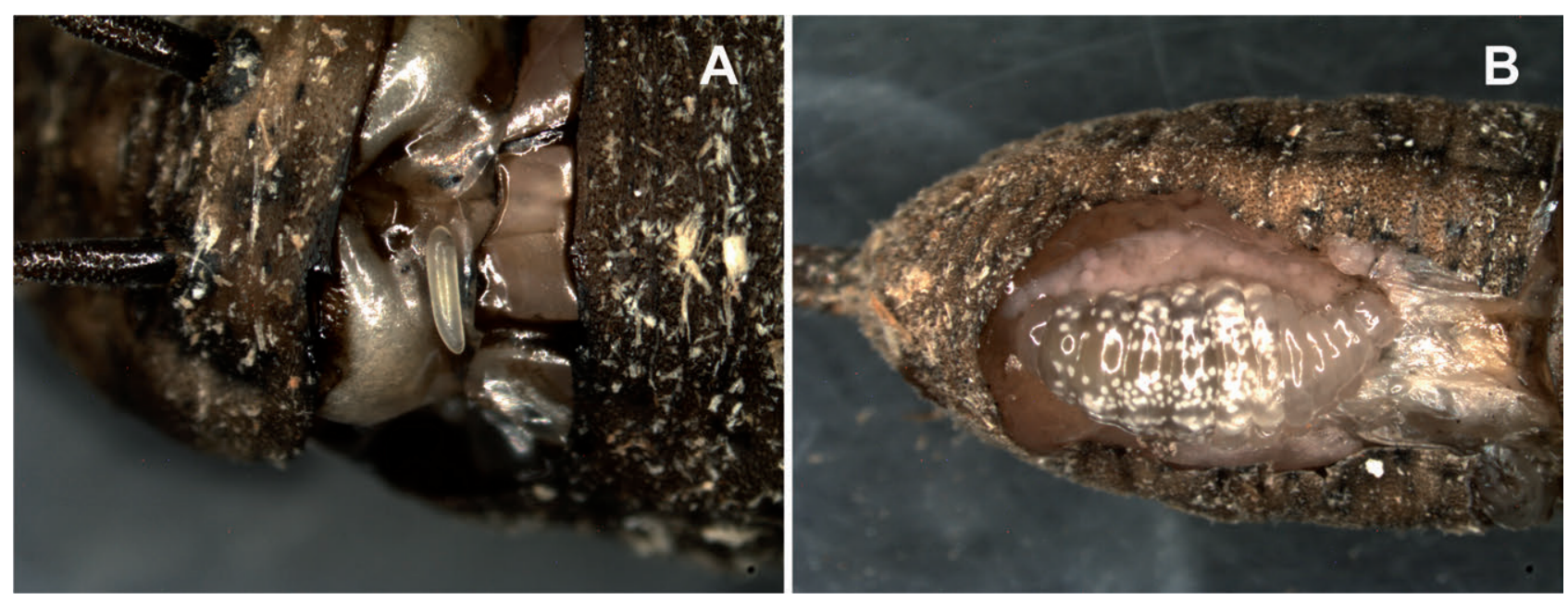

Fig. 2. Preimaginal stages of Rhembobius quadrispinus. A - egg; B - larva.

tively searched for females to mate with, whereas the behaviour of females was to flee. Copulation lasted for 20-60 $\mathrm{s}$ and after mating females tended to ignore males. This ichneumonid is an idiobiont solitary pupal parasitoid and probably arrhenotokous, because in all cases, unfertilized females only produced male offspring.

When a Rhembobius female was placed in a container with pupae, she first apparently walked at random until she found a pupa. Then she checked the pupa by drumming it with her antennae before mounting it. She walked on the pupa before starting to probe and drill. Oviposition normally occurred at the front of the pupa, close to the suture line between the opercular plates. Although R. quadrispi$n u s$ is a solitary pupal parasitoid, the dissection of parasitized pupae revealed that females oviposited from 1 to 4 eggs. These eggs were located between the head and thorax of the host (Fig. 2A), and hatched between 2 and 3 days after oviposition. One day later only one of the larvae was still alive. The larvae took between 10 and 13 days to complete their development (Fig. 2B). At the end of this period the mature larva stopped feeding and started to spin a silk cocoon. Once the cocoon was finished, the larva excreted a meconium. The pupal period lasted between 9 and 12 days. The total developmental time was 22-31 days. The adult used its mandibles to chew a small irregular circular opening in the wall of its host's pupa, usually at the anterior end, through which it emerged.

In some of the pupae of E. tenax collected in the field the duration of immature development of $64 \%$ of the Rhembobius was 4-6 months (126-157 days for males and 154-176 for females), even when the initial period of oviposition was unknown. As they took less time to complete their development in the laboratory (22-31 days; see the following host suitability experiments) it is likely they undergo diapause.

\section{Suitability of E. tenax and Eristalinus aeneus as hosts for $R$. quadrispinus}

Our results show that the percentage of $R$. quadrispinus that emerged from puparia of E. tenax was almost the same as in the case of Eristalinus aeneus $(27.44 \% \mathrm{n}=214$ vs
$26 \% n=61$ ). Under controlled conditions the suitability of both hosts is very similar, but the developmental times of the parasitoid on these two hosts differed.

When E. tenax was the host the total development time of R. quadrispinus (from egg-to-adult) was $25.69 \pm 0.49$ days, $\mathrm{n}=56$ (males: $24.80 \pm 0.42, \mathrm{n}=47$; females: $30.22 \pm 1.26$, $\mathrm{n}=9$ ) and for $E$. aeneus it was $22.09 \pm 1.03$ days (males $\mathrm{n}=11$; females: $\mathrm{n}=0$ ). In addition the male pre-imaginal period on both hosts also differed significantly $[\mathrm{F}(1,56)=$ 7.304, $\mathrm{P}=0.009$ ].

It should be noted that data for six pupae were excluded from the above analysis because the parasitoid took about six months to emerge from the pupae ( 3 males from $E$. tenax pupae and 1 male and 2 females from $E$. aeneus pupae). This indicates that in the field some $R$. quadrispinus spend a period in diapause in the pupae of their hosts, which was the case for all the females that emerged from Eristalinus aeneus pupae.

\section{Effects of host age on the offspring of $R$. quadrispinus}

Females of $R$. quadrispinus laid eggs in pupae of $E$. tenax from one to six days old. Nevertheless, a high percentage of syrphids emerged from pupae that were para-

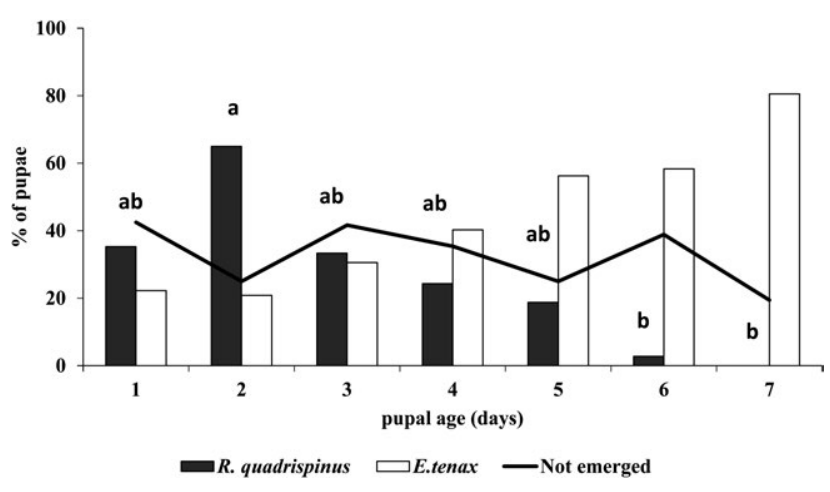

Fig. 3. Percentage of pupae exposed to parasitism at different ages from which wasps and syrphids emerged. A total of 214 E. tenax pupae were used $(32,44,40,36,24,20$ and 20 from each age group respectively). The different letters above the columns of percentages indicate statistically significant differences $(\mathrm{p}<0.05)$. 
sitized when 1 or 2 days old (Fig. 3). There were no significant differences between pupae that were between 1 and 5 days old, but the high percentage of parasitism of 2 day-old pupae is remarkable when compared with that of 6 or 7 day-old pupae $[\mathrm{F}(6,25)=4.201, \mathrm{P}=0.005]$.

The progeny produced by the parasitoids obtained from all age groups of host pupae were all males. Their developmental time was not significantly affected by host pupal age $[F(5,50)=0.551, P=0.737)$, but increased slightly with host pupal age (data of those that entered diapause were not included) (Table 1).

\section{Effect of age of female parasitoid on parasitism}

The success of parasitism decreases inversely with the age of the female (Fig. 4). In the case of $R$. quadrispinus, percentage success ranges from $40.45 \%$ for females that were 1-7 days old to $10.94 \%$ for those that were $15-21$ days old. No pupae were parasitized when the parasitoids were more than one month old. Moreover, the percentage of $E$. tenax pupae that were not parasitized varied from 25 $65 \%$ and increased with the age of the female parasitoid.

\section{Changes in the weight of host pupae during Rhembobius development}

We compared the changes in the weights of non-parasitized pupae of E. tenax and those parasitized at different ages.

Significant morphological changes occurred during the metamorphosis of the E. tenax pupae (Fig. 5). On the first day, the contents of the pupa consisted of a shapeless pink mass. On the second day, the head, thorax and abdomen of the imago along with traces of its wings and legs, inside a transparent membrane, could be distinguished. On the fourth day, sclerotized structures such as legs, mouthparts, eyes and wing sketches were observed. On the sixth day the sclerotization of the thorax was evident, as well as setae on the legs and eyes, and claws on the tarsi. On the last day, the seventh, the membrane started to rupture and the setae on the thorax and abdomen were well developed.

The weight of both male and female pupae of E. tenax gradually decreased during metamorphosis, regardless of body size (Fig. 6). However, after parasitism the pattern differs depending on the age of the pupa when parasitized (Fig. 7).

In the case of pupae that were parasitized when they were 1 or two days old, the slope of the graph is similar in-

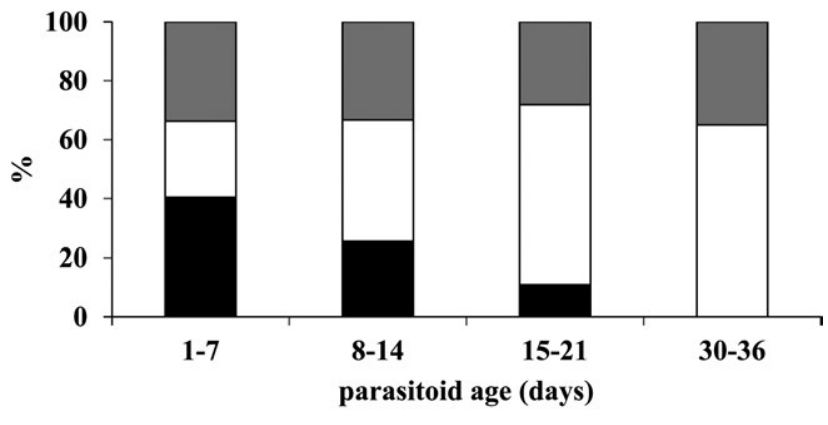

$\square$ R. quadrispinus $\square$ Syrphid $\square$ Not emerged

Fig. 4. Percentage of pupae exposed to parasitism by parasitoids of different ages from which parasitoids, syrphids or nothing emerged.

dicating a gradual decrease in weight similar to that of nonparasitized pupae, but was more prolonged and continued to the $15 / 16^{\text {th }}$ day (Fig. 7A). The slope then decreased more slowly until the parasitoid emerged. The initial slope of the decrease in weight coincides with the egg and larval development of $R$. quadrispinus. During the parasitoid pupal period (from $15 / 16^{\text {th }}$ day) the host pupae lost weight more slowly. However, if the pupae were 3 or 4 days old when parasitized, weight reduction was only gradual up to $5 / 6^{\text {th }}$ day, which corresponds to period when the egg of the parasitoid is developing (Fig. 7B). From this moment, there is a short period of 3-4 days during which there was little change in weight and then the slope of the curve is more pronounced than previously. During this period, parasitoid larval development occurs with the first few days being the period when the very small $(2-3 \mathrm{~mm})$ first instar larva develops. The slope of the curve increases when the parasitoid larva reaches the last instar, which is about $1 \mathrm{~cm}$ long. If parasitism occurs at the end of syrphid pupation, the slope of the decrease in weight is clearly less pronounced than in the previous cases during the first 9-10 days, coinciding with the developments of egg and first instar larva of the parasitoid. After this, the decrease in weight was pronounced and continued until the end of the larval development of the parasitoid (see Fig. 7C).

\section{DISCUSSION}

In the study area the pupae of Eristalis tenax and Eristalinus aeneus were attacked by two species of parasitoid. The most abundant species was Diapria conica and

TABLE 1. Number of $E$. tenax pupae exposed to parasitism by $R$. quadrispinus, percentage of pupae parasitized, preimaginal period of parasitoid (mean $\pm \mathrm{SE}$ ) and percentage of pupae from which adult syrphids emerged; pupae were exposed to parasitism at different ages.

\begin{tabular}{cccc}
\hline Pupal age (days) & Number of pupae offered & $\%$ of pupae parasitized & $\begin{array}{c}\text { Developmental time (days) } \\
\text { adult syrphids emerged }\end{array}$ \\
\hline 1 & 32 & 30.30 & $24.70 \pm 1.00$ \\
2 & 44 & 52.27 & $25.19 \pm 0.89$ \\
3 & 40 & 28.95 & $27.10 \pm 0.99$ \\
4 & 36 & 25 & $26.11 \pm 1.45$ \\
5 & 24 & 20.83 & $26.25 \pm 0.85$ \\
6 & 20 & 5 & 26 \\
7
\end{tabular}




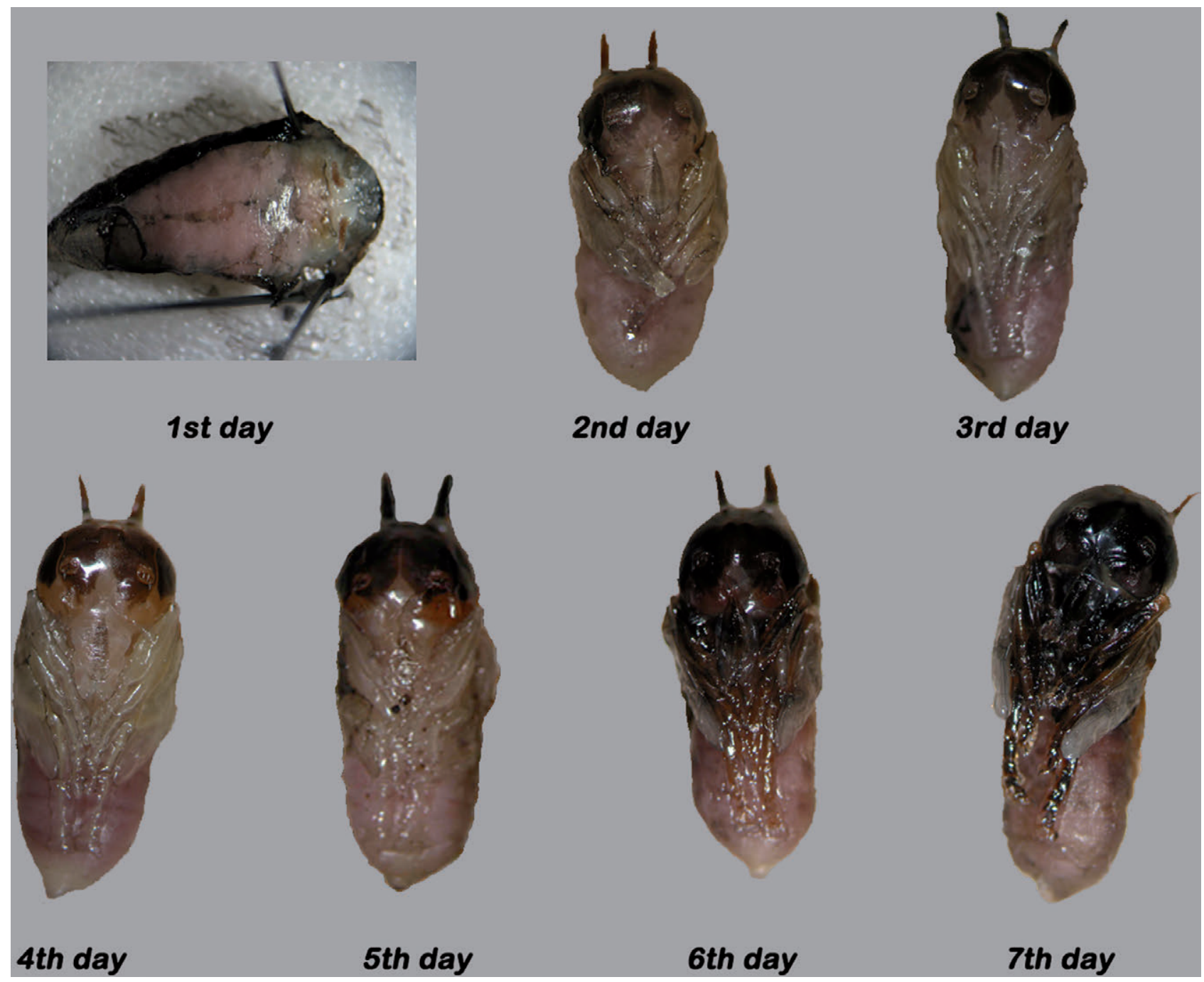

Fig. 5. Morphological changes that occurred during the metamorphosis of pupae of E. tenax.

Rhembobius quadrispinus only emerged from $1 \%$ of the pupae collected. Diapriidae is a large family with about 2,300 species, which are mainly endoparasitoids of Diptera (Masner, 2006). Both D. conica and R. quadrispinus were recorded parasitizing pupae of $E$. tenax. This concurs with Blanchot (1994), who also indicates that Rhembobius

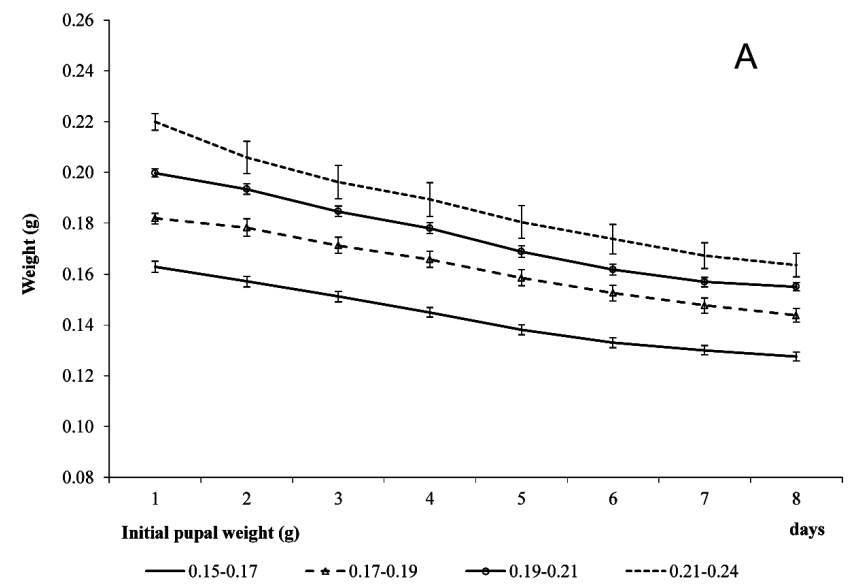

is less frequently recorded parasitizing pupae of $E$. tenax than Diapria. The host of Diapria conica is mainly cited as pupae of E. tenax (Sanders, 1911; Maneval, 1937; Nixon, 1980; Masner 2006) but it also parasitizes those of E. aeneus and E. arbustorum (Fabritius, 1990).

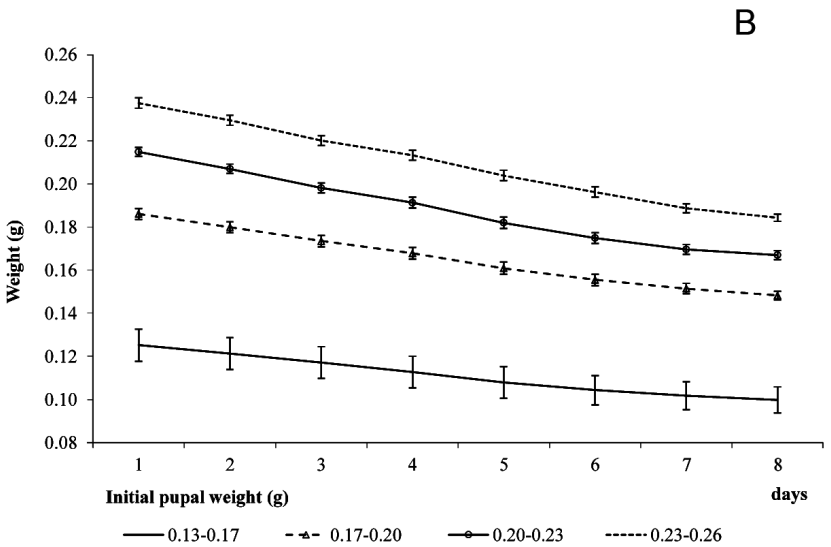

Fig. 6. Changes that occurred in the weight of the pupae of $E$. tenax during metamorphosis: $\mathrm{A}-$ males $(0.15-0.17 \mathrm{n}=8 ; 0.17-0.19$ $\mathrm{n}=11 ; 0.19-0.21 \mathrm{n}=13 ; 0.21-0.24 \mathrm{n}=8)$; B - females $(0.13-0.17 \mathrm{n}=4 ; 0.17-0.20 \mathrm{n}=10 ; 0.20-0.23 \mathrm{n}=18 ; 0.23-0.26 \mathrm{n}=11)$. 

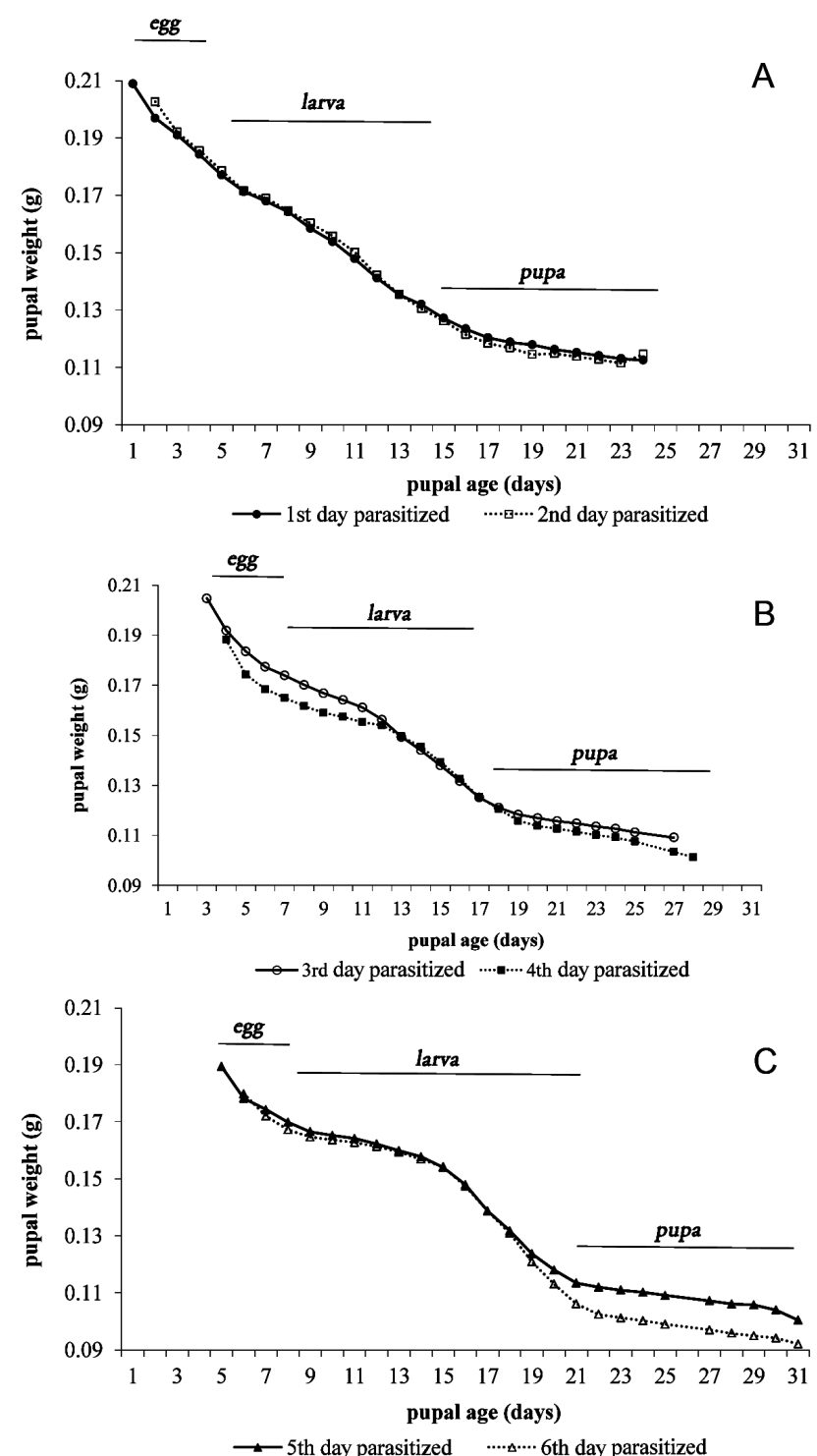

Fig. 7. Changes that occurred in the weight of the pupae that were parasitized (A) on the $1^{\text {st }}$ and $2^{\text {nd }}$ day following pupation $(\mathrm{n}=14),(\mathrm{B})$ on $3^{\text {rd }}$ and $4^{\text {th }}$ day $(\mathrm{n}=9)$, and $(\mathrm{C})$ on $5^{\text {th }}$ and $6^{\text {th }}$ day $(\mathrm{n}=5)$.

The annual activity of both these parasitoids is synchronized with the maximum availability of the pupae of their hosts. Rhembobius wasps were mainly recorded during early summer and autumn in the study area. Females have been collected in December in northern Europe, which indicates they overwinter as adults (Schwarz \& Shaw, 2010). However, we recorded that both males and females were able to delay their development during periods of adverse environmental conditions (diapause) and successfully overwinter inside pupae of E. tenax and Eristalinus aeneus.

Under laboratory conditions, males of $R$. quadrispinus need 24 days to complete their development. However females need about one month and live two or three times longer (19-20 days) than males (7-8 days), which facilitates their search for suitable hosts.

Although the pupae of Eristalinus aeneus $(0.09 \pm 0.001 \mathrm{~g}$, $\mathrm{n}=82)$ are smaller than those of E. tenax $(0.20 \pm 0.002 \mathrm{~g}$, $\mathrm{n}=82$ ), our results indicate that the percentage parasitism of both species is similar, despite size being a very important factor determining the suitability of hosts under laboratory conditions (Vinson \& Iwantsch, 1980; Godfray, 1994). However, under controlled conditions, the small size of hosts is associated with a shorter developmental time, at least, for males. Nevertheless, we believe that in nature, host availability is the main factor determining selection. In the study area, there were more pupae of $E$. tenax than E. aeneus, which accounts for its higher percentage parasitism, however, under controlled conditions there is no difference in the percentage parasitism of these two hosts. In fact, Pisica \& Fabritius (1979) record that on pig and chicken farms in Romania $0.75-6.06 \%$ of the pupae E. tenax and $14.14 \%$ of those of E. aeneus are parasitized by $R$. quadrispinus.

On the other hand, the age of the pupa of the host affected the production of offspring by $R$. quadrispinus as individuals that developed in old pupae produced fewer progeny than those that developed in young pupae, as is recorded for other pupal parasitoids (Chabora \& Pimentel, 1966). The quantity of food available for developing parasitoids is likely to decrease with host age if the adult tissues of the host are a less suitable food source for them (Ueno, 2004). Therefore, the age of a pupa is an important factor determining its suitability as a host for pupal parasitoids (Fuester et al., 1989; King, 1990; Ueno, 1997). This is known to be the case for other types of parasitoids (Patel \& Habib, 1993; Husni et al., 2001; Amalin et al., 2005).

Rhembobius quadrispinus parasitized pupae throughout almost the entire period of syrphid pupation, except the last two days prior to hoverfly emergence. Moreover, the developmental times of the immature stages did not differ significantly when they developed in syrphid pupae of different age. Similar results are reported by Husni et al. (2001) for Brachymeria lasus (Walker, 1841). On the other hand, an important feature affecting the success of female parasitoids is their age. As occurs in other species, old females produce few offspring (Amalin et al., 2005). In $R$. quadrispinus, this reduction in the effectiveness of the parasitoid is associated with an increase in syrphid survival.

During the metamorphosis of this host, the weight of the pupae decreases gradually, due to natural dehydration associated with adult emergence. However, if pupae are parasitized, the pattern in the decrease in the weight of pupae is different. Some differences occur regardless of the age of the pupae when parasitized. When one or two day old pupae are parasitized the decrease in the weight of the pupae is similar to that recorded for non-parasitized pupae. Nevertheless, if parasitism occurs later, the age of the pupae clearly affects the rate at which they lose weight. After a period when there is little decrease in weight (plateaulike) there is a marked difference in the decrease in weight, which is positively associated with the age at which the pupae were parasitized. This indicates that first instar larvae may have difficulty digesting newly developed and sclerotized adult tissue. But if they are able to survive and reach the last larval instar, which are able to eat and quick- 
ly digest these sclerotized tissues, they can complete their development. In fact, almost all the dead larvae recorded when dissecting parasitized pupae at the end of syrphid pupation were first instar larvae.

\section{REFERENCES}

Amalin D.M., Peña J.E. \& Duncan R.E. 2005: Effects of host age, female parasitoid age, and host plant on parasitism of Ceratogramma etiennei (Hymenoptera: Trichogrammatidae). — Fla Entomol. 88: 77-82.

Arthur A.P. \& WyLIE H.G. 1959: Effects of host size on sex ratio, developmental time and size of Pimpla turionellae (L.) (Hymenoptera: Ichneumonidae). — Entomophaga 4: 297-301.

BirTele D. 2004: Short Notes. 53. Hymenoptera, Ichneumonidae. In Cerretti P., Hardersen S., Manson F., Nardi G., Tisato M. \& Zapparoli M. (eds): Invertebrati di una foresta della Pianura Padana, Bosco della Fontana, Secondo contributo. Conservazione Habitat Invertebrati. Vol. 3. Cierre Grafica Editore. Verona, pp. 294-295.

BlANCHOt P. 1994: Inventaire des parasitöides des mouches synanthropes recensés en France. EPHE Biol. Evol. Insectes 7/8 111-119.

Catts E.P. \& Mullen G.R. 2002: Myiasis (Muscoidea, Oestroidea). In Mullen G. \& Durden L. (eds): Medical and Veterinary Entomology. Academic Press, San Diego, CA, pp. 319-348.

Chabora P.C. \& Pimentel D. 1966: Effect of host (Musca domestica Linnaeus) age on the pteromalid parasite Nasonia vitripennis (Walker). - Can. Entomol. 98: 1226-1231.

Charnov E.L. \& Skinner S.W. 1984: Evolution of host selection and clutch size in parasitoid wasps. - Fla Entomol. 67: 5-21.

Constantineanu M.I. \& Mustata G. 1973: Ichneumonidae (Hym. Ichneum.) obtained from cultures of insect pests on vegetables in Moldova. Stud. Comun. Stiint. Natur. Muz. Jud. Suceava 3: 325-352 [in Romanian].

Corrigan J.E. \& Lashomb J.H. 1990: Host influences on the bionomics of Edovum puttleri (Hymenoptera: Eulophidae): Effects on size and reproduction. - Environ. Entomol. 19: 1496-1502.

FABRITIUS K. 1990: The entomophages of synanthropic flies in Romania: larval and pupal parasites. In: Papers from the Symposium on Entomophages and their Role in Preserving the Natural Balance. University Al. I. Cuza, Iasi, pp. 23-30 [in Romanian].

Fischer O.A., Mátlová L., Dvorská L., Švástová P., Bartoš M., Weston R.T. \& Pavlík I. 2006: Various stages in the life cycle of syrphid flies (Eristalis tenax; Diptera: Syrphidae) as potential mechanical vectors of pathogens causing mycobacterial infections in pig herds. - Folia Microbiol. 51: 147-153.

Fuester R.W., Taylor P.B. \& Eisenberg A. 1989: Suitability of prepupae and pupae of the Gypsy moth (Lepidoptera: Lymantriidae) as hosts of Coccygomimus disparis (Hymenoptera: Ichneumonidae). - Environ. Entomol. 18: 338-341.

Gladis T. 1994: Aufbau und Nutzung einer Massenzucht von Eristalis tenax (Diptera, Syrphidae) in der Genbank Gatersleben. - Insecta (Berlin) 1: 287-294.

Godfray H.C.J. 1994: Parasitoids: Behavioral and Evolutionary Ecology. Princeton University Press, Princeton, 488 pp.

HorstmanN K. 2000: Die westpaläarktischen Arten von Ethelurgus Forster, 1869 und Rhembobius Forster, 1869 (Hymenoptera, Ichneumonidae, Cryptinae). - Entomofauna 21(8): 65-76.

HusNi Y., KaINOH Y. \& HondA H. 2001: Effects of host pupal age on host preference and host suitability in Brachymeria lasus
(Hymenoptera: Chalciddieae). - Jap. J. Appl. Entomol. Zool. 36: $97-102$.

KING B.H. 1987: Offspring sex ratios in parasitoid wasps. $-Q$. Rev. Biol. 62: 367-396.

King B.H. 1990: Sex ratio manipulation by parasitoid wasp Spalangia cameroni in response to host age: a test of the hostsize model. - Evol. Ecol. 4: 149-156.

Maneval H. 1937: Serphoidea de la faune Belge. - Bull. Mus. R. Hist. Nat. Belg. 13(22): 1-28.

MASNer L. 2006: Diapriidae. In Fernández F. \& Sharkey M. (eds): Introducción a los Hymenoptera de la Región Neotropical. Sociedad Colombiana de Entomología y Universidad Nacional de Colombia, Bogotá, pp. 615-618.

NIXoN G.E.J. 1980: Diapriidae (Diapriinae) Hymenoptera, Proctotrupoidea. Handbooks for the Identification of British Insects Vol. 8, Part 3(di). Royal Entomol. Society, London, 55 pp.

Otтo M. \& Mackauer M. 1998: The developmental strategy of an idiobiont ectoparasitoid, Dendrocerus carpenteri: influence of variations in host quality on offspring growth and fitness. Oecologia 117: 353-364.

Patel P.N. \& Habib M.E.M. 1993: Microcharops anticarsiae (Hym.: Ichneumonidae), parasitoid of Anticarsia gemmamtalis (Lep.: Noctuidae): host age preference, sex ratio effects and functional response. - Entomophaga 38: 511-517.

PISICA C. 1983: Ichneumonidae (Hym.) parasitizing Diptera in România. An. St. Univ. "Al. I. Cuza” Iasi (Sect. IIa, Biol.) 29: 9-12.

Pisica C. \& Fabritius K. 1979: Untersuchungen über Parasiten synanthroper Syrphiden (Diptera). I. Ichneumonidae (Hymenoptera). Anuaral Muz. Stiint. Natur. Piatra Neamt (Ser. Bot.Zool.) 4: 215-216.

Rotheray G.E. 1993: Colour guide to hoverfly larvae (Diptera, Syrphidae) in Britain and Europe. — Dipterists Digest 9, 156 pp.

Rotheray G.E. \& MacGowan I. 2000: Status and breeding sites of three presumed endangered Scottish saproxylic syrphids (Diptera, Syrphidae). - J. Insect Conserv. 4: 215-223.

SANDERS G.E. 1911: Notes on the breeding of Tropidopria conica Fabr. - Can. Entomol. 43: 48-50.

Schwarz M. \& Shaw M.R. 2010: Western Palaearctic Cryptinae (Hymenoptera: Ichneumonidae) in the National Museums of Scotland, with nomenclatural changes, taxonomic notes, rearing records and special reference to the British check list. Part 4. Tribe Phygadeuontini, subtribes Mastrina, Ethelurgina, Endaseina (excluding Endasys), Bathythrichina and Cremnodina. —Entomol. Gaz. 61: 187-206.

Sedivy J. 1986: The hosts of Ichneumon flies in Europe (Hymenoptera, Ichneumonidae). Acta Entomol. Bohemoslov. 83: $10-23$.

UENO T. 1997: Host age preference and sex allocation in the pupal parasitoid Itoplectis naranyae (Hymenoptera: Ichneumonidae). - Ann. Entomol. Soc. Am. 90: 640-645.

UENO T. 2004: Offspring performance in the pupal parasitoid Pimpla (= Coccygomimus) luctuosa (Hymenoptera: Ichneumonidae) as influenced by host age and size. - J. Fac. Agric. Kyushu Univ. 49: 321-329.

VINSON S.B. \& IwANTSCH G.F. 1980: Host suitability for insect parasitoids. - Annu. Rev. Entomol. 25: 397-419.

Yu D.S., Van Achterberg K. \& Horstmann K. 2005: World Ichneumonoidea 2004. Taxonomy, Biology, Morphology and Distribution. Taxapad, CD/DVD, Vancouver, Canada.

Received April 17, 2013; revised and accepted January 17, 2014 Prepublished online April 23, 2014 